\title{
Predictive value of corrected thrombolysis in myocardial infarction frame count for fractional flow reserve: an easy tool for patient selection
}

\author{
Muhammet Cebeci ${ }^{1}$, Mustafa Karanfil ${ }^{2}$, Serkan Topaloğlu² \\ 1 Söke State Hospital, Cardiology Clinic, Aydin, Turkey \\ 2 Ankara City Hospital, Department of Cardiology, Ankara, Turkey
}

\section{KEY WORDS}

coronary artery

disease, corrected

TIMI frame count, fractional flow reserve
Correspondence to:

Mustafa Karanfil, MD,

Ankara City Hospital,

Department of Cardiology,

Üniversiteler, Bilkent Blv. No:1,

06800 Çankaya/Ankara, Turkey,

phone: +905555095850

email: mkaranfil42@yahoo.com

Received: December 21, 2019.

Revision accepted:

March 14, 2020.

Published online: March 17, 2020.

Kardiol Pol. 2020; 78 (4): 311-317

doi:10.33963/KP.15237

Copyright by the Author(s), 2020

\section{ABSTRACT}

BACKGROUND Treatment of moderate stenosis of all coronary arteries remains a challenge for interventional cardiologists. Usually, the hemodynamic significance of moderate stenosis has to be assessed in the catheter laboratory. Fractional flow reserve (FFR) is the preferable method, but it is an invasive technique associated with additional costs. Corrected thrombolysis in myocardial infarction frame count (CTFC) is a simple, repeatable, objective, noninvasive, and quantitative method that allows an indirect assessment of microvascular dysfunction and epicardial coronary stenosis. Only $40 \%$ of moderate stenosis cases are found to be hemodynamically severe after FFR measurement; therefore, an additional test would help avoid the use of this invasive tool in the remaining $60 \%$ of patients.

AIMS We aimed to assess the value of CTFC for predicting FFR.

METHODS A total of 238 consecutive patients who underwent FFR for the assessment of moderate stenosis were enrolled. Coronary angiography records were used to calculate cTFC. Patients were divided into 2 groups: with an FFR value of less than 0.8 (FFR+) and an FFR value of 0.8 or higher (FFR-).

RESULTS We noted a significant correlation between CTFC and FFR when used both as a categorical and continuous variable. The CTFC of the FFR+ group was higher as compared with that of the FFR-group (27.68 [11.79] vs $20.39[8.39] ; P<0.001)$. In the receiver operating characteristic curve analysis, the sensitivity and specificity of the test for predicting FFR below 0.8 were $82 \%$ and $52 \%$, respectively, at the cutoff cTFC value of 19.

CONCLUSIONS Our study showed that cTFC can predict FFR. Moreover, it can be used for patient selection for FFR measurement and as a basic physiological assessment tool for moderate coronary stenosis.

INTRODUCTION Treatment of moderate stenosis of all coronary arteries remains a challenge for interventional cardiologists, and the importance of assessing the ischemic potential of such stenosis is often underestimated. 'There is a high degree of variability among observers in the visual assessment of the severity of moderate lesions during coronary angiography. ${ }^{2-5}$ Percutaneous coronary intervention (PCI) performed on the basis of the operator's visual assessment may be associated wit 2 potential problems: a lesion that does not cause ischemia can be treated unnecessarily and a lesion causing ischemia can also be left untreated. If the noninvasive assessment was not performed before coronary angiography, it is particularly important to evaluate the hemodynamic significance of moderate lesions in the catheter laboratory. Fractional flow reserve (FFR) is the preferred method in clinical practice. It can be defined as the ratio of the mean 


\section{WHAT'S NEW?}

To the best of our knowledge, this is the first study that demonstrated the value of corrected thrombolysis in myocardial infarction frame count (CTFC) for predicting fractional flow reserve (FFR). While CTFC can be acquired from basal angiographic records, FFR is measured by an extra guidewire with pressure detection sensors on it. The FFR guidewire should pass the stenosis to detect a difference in pressure; therefore, it is associated with the risk of complications and adds an extra cost to the procedure. Our study demonstrated that CTFC, which can be obtained without additional cost and intervention, can predict FFR with a sensitivity and specificity similar to those of an exercise stress test. Moreover, our results show that cTFC has the potential to guide patient selection for FFR and facilitate cost-effective diagnostic procedures.

distal coronary pressure (Pd) to mean aortic pressure $(\mathrm{Pa})$ during maximal hyperemia. ${ }^{6}$

An important advantage of FFR is that it provides prognostic information. Generally, it is believed that patients with moderate coronary stenosis with an FFR exceeding 0.75 can be spared interventional treatment. ${ }^{3,7-15} \mathrm{Al}$ though FFR measurements are useful in clinical practice, the technique is limited by its invasiveness and additional cost. The FFR measurement is not only related to the degree of coronary stenosis, but also coronary microvascular disease affects FFR. Although there is currently no technique that can directly assess the microvascular bed in humans, the corrected thrombolysis in myocardial infarction frame count (cTFC) is a simple repeatable, objective, noninvasive, and quantitative tool that allows an indirect assessment of microvascular dysfunction and epicardial coronary stenosis. ${ }^{7}$ The prognostic value of a combination of FFR and CTFC measurements has been reported. ${ }^{16}$ However, there have been no studies investigating the value of CTFC for predicting FFR. The measurement of FFR is an invasive method associated with an extra cost and the risk of complications such as coronary dissection. ${ }^{17}$ If cTFC can predict FFR, its calculation could facilitate patient selection for FFR assessment, thus reducing the unnecessary use of FFR in moderate coronary lesions. Therefore, the aim of our study was to evaluate the role of CTFC in predicting FFR.

METHODS The study included 238 consecutive patients who underwent FFR measurement for one coronary artery in our hospital. The FFR values were obtained from catheter laboratory records, while cTFC was calculated retrospectively on the basis of coronary angiography records. Other variables were obtained from patient medical records.

Coronary angiographies of patients who underwent FFR were evaluated. For CTFC calculation, the best angiographic view of the proximal and distal part of the artery included in the FFR measurement was chosen. cTFC measurements were calculated by operators who were blinded to the FFR from angiographic images, which were obtained before giving vasodilators used for FFR. In accordance with the literature, the first frame was accepted as the frame that was reached by contrast agent to both walls of the target artery. The last frame was determined as the moment the contrast agent entered the distal region, in line with literature data. These standardized regions were the first branch of the posterolateral artery for the right coronary artery; the distal obtuse marginal branch that includes the culprit lesion for the left circumflex artery; and distal bifurcation (also known as the "moustache," "pitchfork," or "whale's tail") of the left anterior descending artery (LAD). Since the LAD is longer than the other 2 arteries, the values for the LAD were divided by 1.7 .

As the rate of coronary angiography imaging in our hospital was 15 frames per second, the values obtained were multiplied by 2 . Contrast agent was injected manually in all evaluated images. Images taken after nitrate injection were not evaluated. $7 \mathrm{~F}$ guiding catheters without side holes and 0.014 pressure wires were used. Before the procedure, an intravenous bolus of heparin was administered according to the weight of each patient. After calibration and basal measurements, to ensure maximal hyperemia, $200 \mathrm{mg}$ of isosorbide mononitrate and adenosine were administered by the intracoronary route using a guiding catheter. Adenosine at a dose of $100 \mathrm{mg}$ for the right coronary artery and $100 \mathrm{mg}$ for the left coronary artery system was administered. If FFR was higher than 0.8 for the left coronary artery system, the test was repeated with $200 \mathrm{mg}$ of adenosine. Baseline FFR was measured as the ratio of baseline Pd to baseline Pa before hyperemia was achieved. Following maximal hyperemia, FFR was calculated as the ratio of mean Pd to mean Pa. FFR lower than 0.8 was accepted as hemodynamically relevant, in line with literature data. ${ }^{3,18-20}$

There were no tandem lesions, chronic total occlusions, or severe valvular diseases that could affect FFR measurements. In all patients, one vessel was assessed with FFR (238 vessels). There were 228 lesions in the LAD; 2 , in the left main coronary artery; 5, in the left circumflex artery; and 2 , in the right coronary artery.

To evaluate the predictive value of CTFC for FFR measurement, patients were divided into 2 groups based on FFR: FFR+ group (hemodynamically significant; FFR <0.8) and FFR-group (hemodynamically insignificant; FFR $\geq 0.8$ ). Demographic and clinical characteristics of patients were compared, and correlations between CTFC and FFR measurements were evaluated.

The study was approved by the ethics committee of the local hospital and was carried out in accordance with the Declaration of Helsinki. 
TABLE 1 Comparison of baseline demographic and laboratory parameters between patients with fractional flow reserve value of less than 0.08 (FFR+) and of 0.8 or higher (FFR-)

\begin{tabular}{|c|c|c|c|c|}
\hline Parameter & & $F F R+(n=106)$ & FFR- $(n=132)$ & $P$ value \\
\hline \multirow[t]{2}{*}{ Age, y } & Mean (SD) & $61.59(9.89)$ & $63.53(9.23)$ & \multirow[t]{2}{*}{0.12} \\
\hline & Median (IQR) & $61(54-70)$ & $63(57-70)$ & \\
\hline Male sex, n (\%) & & $82(77)$ & $93(70)$ & 0.24 \\
\hline \multirow[t]{2}{*}{ Glucose, mg/dl } & Mean (SD) & $128.69(56.68)$ & $122.11(48.92)$ & \multirow[t]{2}{*}{0.48} \\
\hline & Median (IQR) & $110.5(93-135.5)$ & $104.50(93.5-136.5)$ & \\
\hline \multirow[t]{2}{*}{ Urea, mg/dl } & Mean (SD) & 40.67 (18.71) & $38.42(15.35)$ & \multirow[t]{2}{*}{0.49} \\
\hline & Median (IQR) & $35(30-45)$ & $35.5(30-43)$ & \\
\hline \multirow[t]{2}{*}{ Creatinine, $\mathrm{mg} / \mathrm{dl}$} & Mean (SD) & $0.99(0.55)$ & $0.98(0.59)$ & \multirow[t]{2}{*}{0.99} \\
\hline & Median (IQR) & $0.91(0.77-1.07)$ & $0.92(0.77-1.06)$ & \\
\hline \multirow[t]{2}{*}{ AST, IU/I } & Mean (SD) & $28.41(46.42)$ & $22.77(17.53)$ & \multirow[t]{2}{*}{0.15} \\
\hline & Median (IQR) & $20(17-25)$ & $20(16-24.5)$ & \\
\hline \multirow[t]{2}{*}{ ALT, IU/I } & Mean (SD) & $23.92(16.88)$ & $23.12(14.08)$ & \multirow[t]{2}{*}{0.98} \\
\hline & Median (IQR) & $20(14-27)$ & $20(14-27)$ & \\
\hline \multirow[t]{2}{*}{ Total cholesterol, mg/dl } & Mean (SD) & $181.39(45.52)$ & $188.49(39.42)$ & \multirow[t]{2}{*}{0.21} \\
\hline & Median (IQR) & $174(147-205)$ & $191.5(157.5-220)$ & \\
\hline \multirow[t]{2}{*}{$\mathrm{HDL}-\mathrm{C}, \mathrm{mg} / \mathrm{dl}$} & Mean (SD) & $41.54(11.33)$ & 44.79 (16.19) & \multirow[t]{2}{*}{0.09} \\
\hline & Median (IQR) & $40(34-46)$ & $42(36-49.5)$ & \\
\hline \multirow[t]{2}{*}{$\mathrm{LDL}-\mathrm{C}, \mathrm{mg} / \mathrm{dl}$} & Mean (SD) & $105.45(37.17)$ & $115.50(38.57)$ & \multirow[t]{2}{*}{0.048} \\
\hline & Median (IQR) & $97(83-127)$ & $115(85.5-138.5)$ & \\
\hline \multirow[t]{2}{*}{ Triglycerides, mg/dl } & Mean (SD) & $172.88(121.77)$ & $159.17(76.10)$ & \multirow[t]{2}{*}{0.94} \\
\hline & Median (IQR) & $143(100-206)$ & $140(106-200.5)$ & \\
\hline \multirow[t]{2}{*}{$\mathrm{TSH}, \mu \mathrm{U} / \mathrm{ml}$} & Mean (SD) & $1.43(1.28)$ & $1.58(1.46)$ & \multirow[t]{2}{*}{0.16} \\
\hline & Median (IQR) & $1.08(0.67-1.79)$ & $1.24(0.82-1.86)$ & \\
\hline \multirow[t]{2}{*}{ Hemoglobin, g/dl } & Mean (SD) & $13.71(1.83)$ & $14.55(3.83)$ & \multirow[t]{2}{*}{0.15} \\
\hline & Median (IQR) & $14(12.8-14.9)$ & $14.1(13.3-15.2)$ & \\
\hline \multirow[t]{2}{*}{ Platelets, $1000 / \mathrm{ml}$} & Mean (SD) & $259.50(63.42)$ & $252.17(62.52)$ & \multirow[t]{2}{*}{0.47} \\
\hline & Median (IQR) & $252(220-280)$ & $243.5(214.5-292.5)$ & \\
\hline \multirow[t]{2}{*}{ WBC, $1000 / \mathrm{ml}$} & Mean (SD) & $8.73(2.51)$ & $7.94(2.24)$ & \multirow[t]{2}{*}{0.01} \\
\hline & Median (IQR) & $8.24(6.8-10)$ & $7.61(6.51-9.29)$ & \\
\hline NLR & Mean (SD) & $3.7[2.39]$ & $2.43[1.18]$ & $<0.001$ \\
\hline PDW, \% & Mean (SD) & $43.62[9.78]$ & $43.62[9.78]$ & 0.02 \\
\hline Smoking, n (\%) & & $62(58)$ & $58(44)$ & 0.03 \\
\hline Diabetes mellitus, n (\%) & & $62(58)$ & $44(33)$ & $<0.001$ \\
\hline Hypertension, n (\%) & & $69(65)$ & $81(61)$ & 0.59 \\
\hline
\end{tabular}

SI conversion factors: to convert LDL-C and HDL-C to $\mathrm{mmol} / \mathrm{l}$, multiply by 0.0259 ; triglycerides to $\mathrm{mmol} / \mathrm{l}$, by 0.0113 ; glucose to $\mathrm{mmol} / \mathrm{l}$, by 0.0555 .

Abbreviations: ALT, alanine aminotransferase; AST, aspartate aminotransferase; FFR, fractional flow reserve; HDL-C, high-density lipoprotein cholesterol; LDL-C, low-density lipoprotein cholesterol; NLR, neutrophil-to-lymphocyte ratio; PDW, platelet distribution width; TSH, thyroid-stimulating hormone, IQR, interquartile range; WBC, white blood cells

Statistical analysis All statistical analyses were performed using the SPSS statistical package for Windows version 22.0 (SPSS Inc., Chicago, Illinois, United States). Descriptive statistics for numerical variables and number tables for categorical variables were created. All variables were presented as mean (SD) and median with interquartile range. Categorical 
variables were given as percentages. The $\mathrm{X}^{2}$ test was used to analyze differences between categorical variables. The 1-way analysis of variance was used to test for homogeneity, and the Kolmogorov-Smirnov test was applied to test for normality. The independent-sample $t$ test was used for normally distributed variables, and the Mann-Whitney test, for variables without normal distribution. The receiver operating characteristic (ROC) curve analysis was used to assess the predictive value of CTFC for FFR. A $P$ value of less than 0.05 was considered significant.

RESULTS The baseline characteristics of the study groups are presented in TABLE 1. Of the 238 patients enrolled in the study, 175 were male. In 132 patients, the FFR values were lower than 0.8. The FFR+ and FFR- groups did not differ in terms of age, levels of biochemical and hematologic parameters (except low-density lipoprotein cholesterol levels, white blood cell count, neutrophil-to-lymphocyte ratio, and platelet distribution width), or the presence of hypertension (TABLE 1).

There were more active smokers and more patients with diabetes in the FFR+ group than in the FFR- group. Low-density lipoprotein cholesterol levels were lower in the FFR-group than in the FFR+ group. White blood cell count, neutrophil-to-lymphocyte ratio, and platelet distribution width were higher in the FFR+ group (TABLE 1).

The Gensini score was higher in the FFR+ group than in the FFR-group. The adenosine amount used for FFR measurement was higher in the FFR- group than in the FFR+ group. In the FFR+ group, basal FFR measurement values were significantly lower than in the FFR-group. Data are presented in TABLE2.

According to the visual stenosis evaluation, the stenosis degree in the FFR+ group was significantly higher than in the FFR- group. There was no difference in stenosis degree between groups according to the quantitative coronary

TABLE 2 Comparison of angiographic parameters between patients with fractional flow reserve value of less than 0.08 (FFR+) and of 0.8 or higher (FFR-)

\begin{tabular}{|c|c|c|c|c|}
\hline Parameter & & $F F R+(n=10)$ & FFR- $(n=132)$ & $P$ value \\
\hline \multirow[t]{2}{*}{ Gensini score } & Mean (SD) & $35.66(22.38)$ & $19.97(24.03)$ & \multirow[t]{2}{*}{$<0.001$} \\
\hline & Median (IQR) & $32(19-47)$ & $12.0(6-23.5)$ & \\
\hline \multirow[t]{2}{*}{ Adenosine amount } & Mean (SD) & $144.86(41.86)$ & $165.61(43.21)$ & \multirow[t]{2}{*}{$<0.001$} \\
\hline & Median (IQR) & $150(120-150)$ & $150(150-180)$ & \\
\hline \multirow[t]{2}{*}{ Basal FFR value } & Mean (SD) & $0.87(0.06)$ & $0.93(0.03)$ & \multirow[t]{2}{*}{$<0.001$} \\
\hline & Median (IQR) & $0.88(0.83-0.91)$ & $0.94(0.91-0.95)$ & \\
\hline \multirow[t]{2}{*}{ CTFC } & Mean (SD) & $27.68(11.79)$ & $20.39(8.39)$ & \multirow[t]{2}{*}{$<0.001$} \\
\hline & Median (IQR) & $27(20-32)$ & $18(14-25)$ & \\
\hline \multirow{2}{*}{$\begin{array}{l}\text { Stenosis degree (visual } \\
\text { evaluation before FFR) }\end{array}$} & Mean (SD) & $57.26(9.41)$ & $54.70(9.44)$ & \multirow[t]{2}{*}{0.046} \\
\hline & Median (IQR) & $60(50-60)$ & $50(50-60)$ & \\
\hline \multirow[t]{2}{*}{ QCA stenosis degree } & Mean (SD) & $55.60(6.79)$ & $55.06(8.17)$ & \multirow[t]{2}{*}{0.59} \\
\hline & Median (IQR) & $57(51-58)$ & $55.5(49-59)$ & \\
\hline cTFC value ${ }^{a}$, n (\%) & & $87(82)$ & $63(48)$ & $<0.001$ \\
\hline
\end{tabular}

a Used as a categorical variable (cTFC $\geq 19$ accepted as significant)

Abbreviations: cTFC, corrected thrombolysis in myocardial infarction frame count; QCA, quantitative coronary analysis; others, see TABLE 1

TABLE 3 Cross table for categorical analysis of the relationship between corrected thrombolysis in myocardial infarction frame count and fractional flow reserve

\begin{tabular}{lllll} 
FFR & & CTFC & Total & P value \\
& $<19$ & $\geq 19$ & & $<0.001$ \\
\cline { 1 - 3 } & 69 & 63 & 132 & \\
\hline$<0.8$ & 19 & 87 & 106 & - \\
\hline Total & 88 & 150 & 238 & \\
\hline
\end{tabular}




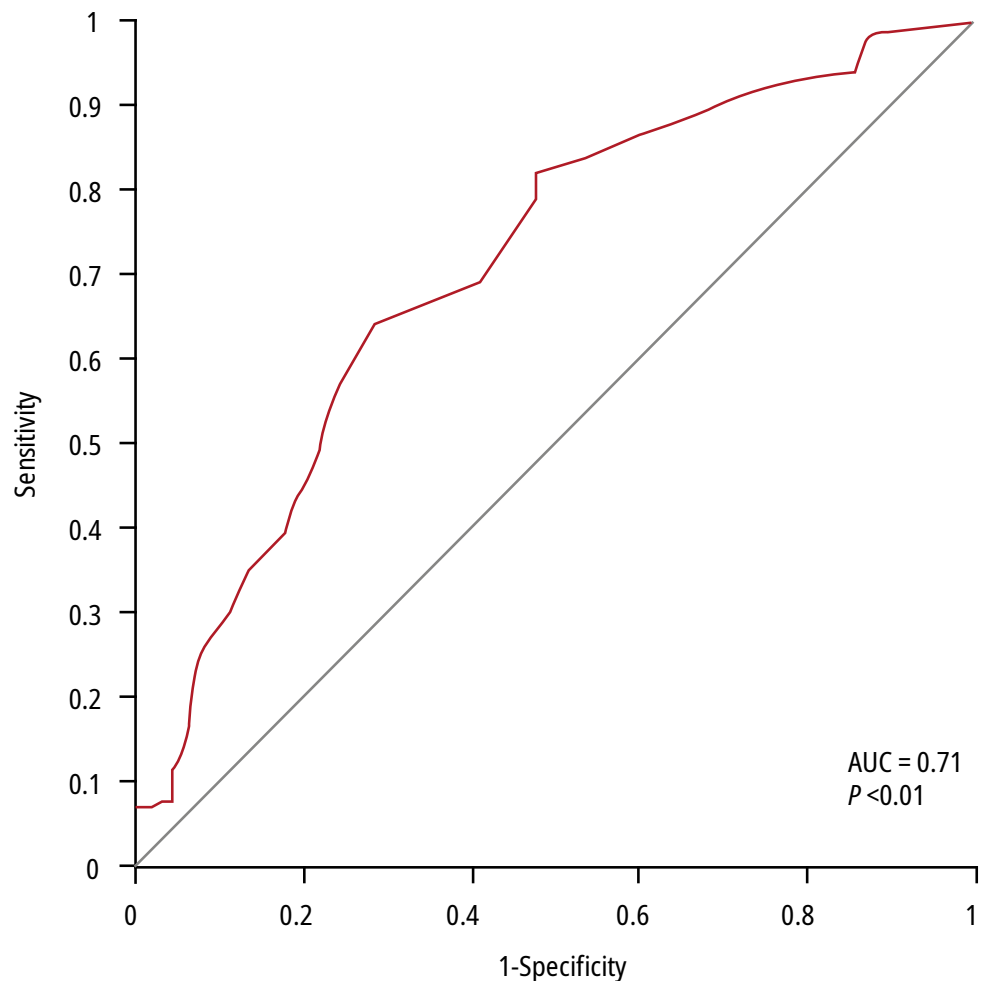

FIGURE 1 Receiver operating characteristic curve analysis of correlation between corrected thrombolysis in myocardial infarction frame count and fractional flow reserve. Diagonal segments are produced by ties.

Abbreviations: AUC, area under the curve
Basal FFR was lower and stenosis degree was higher on visual assessment in the FFR+ group. There was no difference in QCA results between groups. Thus, we can speculate that basal FFR measurements and visual assessment of stenosis can also help predict FFR. However, these findings should be confirmed by well-designed prospective studies.

The amount of adenosine used for the FFR measurement was lower in the FFR+ group. This finding may be due to the fact that operators stopped using adenosine when they reached a significant value in the FFR+ group and used a higher amount of adenosine in the FFR-group to reach a significant value.

Despite strong evidence supporting FFR-guided intervention and guideline recommendations, FFR is still an underused test. ${ }^{21,22}$ This may be due to an extra cost of pressure wires, extra time needed for the test, risk of complications, vessel tortuosity, and need for pharmacological induction of hyperemia. ${ }^{23}$ The rate of using physiological assessment of stenosis is lower than $10 \%$ in most parts of the world. ${ }^{24}$

Another limitation of FFR is that it requires considerable expertise and a careful interpretation of results. Both the procedure itself and subsequent interpretation are prone to numerous flaws. Procedural flaws include those made during setting zero pressure, flushing the pressure lines, as well as pressure mistakes caused by inappropriate engagement of catheters. ${ }^{25}$ While analyzing pressure waveforms, minor flaws can seriously affect test results. It is important to check the accuracy of Pd and Pa waveforms during pressure wire pullback to reduce the risk of such errors. ${ }^{26}$

Because of the above limitations, some novel techniques have been developed. The quantitative flow ratio is a new method that enables computation of FFR by using 3-dimensional reconstructed QCA rendered from 2-dimensional views as well as estimation of contrast flow velocity during angiography obtained from $\mathrm{CTFC} .{ }^{27}$ This technique was found to be well correlated with conventional hyperemia-induced pressure wire-dependent FFR..$^{23,28}$ The quantitative flow ratio has a potential to reduce the need for pressure wires and medical-induced hyperemia by two-thirds. This novel technique can also increase the rate of using physiological assessment of moderate coronary stenosis. However, in contrast to CTFC, the method has some limitations that prevent its wider application in clinical practice. As mentioned above, CTFC can be easily obtained from angiographic records without any additional cost.

Our study showed that CTFC measurement can be used as an auxiliary method for patient selection for FFR. Although FFR measurement is useful for assessing the physiological significance of the lesion and planning 
revascularization in patients with moderate stenosis, only $44 \%$ of cases had an FFR value of less than 0.8. An unnecessary invasive intervention is associated with additional cost and risk of serious complications, such as coronary artery dissection. ${ }^{17}$ Therefore, there is a need for a cost-effective, noninvasive, and highly feasible test that could be used to evaluate coronary blood flow in such patients and to identify patients requiring FFR. In our opinion, CTFC, which can be easily applied after coronary angiography, is a suitable method.

Our results suggest that apart from facilitating patient selection for FFR, cTFC can also be easily used as a basic tool for physiological assessment of stenosis, which is widely underused in clinical practice. We showed a significant association between FFR and CTFC when used both as a categorical and continuous variable. Although the specificity of CTFC measurement for predicting an FFR of less than 0.8 was quite low, the sensitivity was similar to that observed for noninvasive stress tests used to evaluate ischemia. Therefore, the use of FFR measurement in patients with moderate coronary artery disease with increased CTFC seems to be a reasonable approach.

In our study, the negative predictive value of cTFC as a categorical variable ( $\mathrm{CTFC}<19$ ) was $78 \%$. According to this result, the probability of a significant stenosis on FFR measurement is reduced in patients with a CTFC of 18 frames or lower. Therefore, it may be reasonable not to perform FFR measurement in these patients. However, prospective studies are needed to provide data on short- and long-term major cardiovascular events and mortality after FFR assessment is abandoned on the basis of CTFC measurement in this population.

As there were no tandem lesions, chronic total occlusions, or severe valvular diseases in our study population and the number of non-LAD lesions was limited, the results should be interpreted with caution and cannot be extrapolated to a wider population.

In light of our results, CTFC seems to be a safe, practical, and helpful method for patient selection for FFR measurement. Moreover, it is a cost-effective tool for predicting FFR and has a potential to be used as a basic method for physiological assessment of coronary stenosis. Further prospective, multicenter, randomized controlled trials with larger populations and long-term follow-up are needed to confirm the predictive role of CTFC.

\section{ARTICLE INFORMATION}

\section{CONFLICT OF INTEREST None declared.}

OPEN ACCESS This is an Open Access article distributed under the terms of the Creative Commons Attribution-NonCommercial-NoDerivatives $4.0 \mathrm{In}$ ternational License (CC BY-NC-ND 4.0), allowing third parties to download articles and share them with others, provided the original work is properly cited, not changed in any way, distributed under the same license, and used for noncommercial purposes only. For commercial use, please contact the journal office at kardiologiapolska@ptkardio.pl.

HOW TO CITE Cebeci M, Karanfil M, Topaloğlu S. Predictive value of corrected thrombolysis in myocardial infarction frame count for fractional flow reserve: an easy tool for patient selection. Kardiol Pol. 2020; 78: 311-317. doi:10.33963/ KP.15237

\section{REFERENCES}

1 Dimopoulos K, Ghilencea L, La Manna A, Di Mario C. Approach to intermediate lesions. In: Colombo A, Stankovic GM, eds. Problem Oriented Approaches in Interventional Cardiology. Abingdon, United Kingdom: Informa Healthcare; 2007: 123-138.

2 Botman KJ, Pijls NH, Bech JW, et al. Percutaneous coronary intervention or bypass surgery in multivessel disease? A tailored approach based on coronary pressure measurement. Catheter Cardiovasc Interv. 2004; 63: 184-191.

3 Tonino PA, De Bruyne B, Pijls NH, et al. Fractional flow reserve versus angiography for guiding percutaneous coronary intervention. N Engl J Med. 2009; 360: 213-224.

4 Neupane $\mathrm{S}$, Singh $\mathrm{H}$, Edla S, et al. Meta-analysis of fractional flow reserve guided complete revascularization versus infarct related artery only revascularization in patients with ST-elevation myocardial infarction and multivessel coronary artery disease. Coron Artery Dis. 2019; 30: 393-397.

5 Watanabe H, Onishi K, Kakehi K, et al. Clinical and angiographic factors predicting fractional flow reserve and explaining the visual-functional mismatch in patients with intermediate coronary artery stenosis. Coron Artery Dis. 2020; 31: 73-80.

6 Pijls NH, van Son JA, Kirkeeide RL, et al. Experimental basis of determining maximum coronary, myocardial, and collateral blood flow by pressure measurements for assessing functional stenosis severity before and after percutaneous transluminal coronary angioplasty. Circulation. 1993; 87: 1354-1367.

7 Kern MJ, Lerman A, Bech JW, et al. Physiological assessment of coronary artery disease in the cardiac catheterization laboratory: a scientific statement from the American Heart Association Committee on Diagnostic and Interventional Cardiac Catheterization, Council on Clinical Cardiology. Circulation. 2006; 114: 1321-1341

8 Spaan JA, Piek JJ, Hoffman JI, Siebes M. Physiological basis of clinically used coronary hemodynamic indices. Circulation. 2006; 113: 446-455.

9 Kern MJ, Donohue TJ, Aguirre FV, et al. Clinical outcome of deferring angioplasty in patients with normal translesional pressure-flow velocity measurements. J Am Coll Cardiol. 1995; 25: 178-187.

10 Bech GJ, De Bruyne B, Bonnier HJ, et al. Long-term follow-up after deferral of percutaneous transluminal coronary angioplasty of intermediate stenosis on the basis of coronary pressure measurement. J Am Coll Cardiol. 1998; 31: 841-847. 11 Pijls NH, van Schaardenburgh P, Manoharan G, et al. Percutaneous coronary intervention of functionally nonsignificant stenosis: 5 -year follow-up of the DEFER Study. J Am Coll Cardiol. 2007; 49: 2105-2111.

12 Ofili EO, Kern MJ, Labovitz AJ, et al. Analysis of coronary blood flow velocity dynamics in angiographically normal and stenosed arteries before and after endolumen enlargement by angioplasty. J Am Coll Cardiol. 1993; 21: 308-316.

13 Donohue TJ, Kern M], Aguirre FV, et al. Assessing the hemodynamic significance of coronary artery stenoses: analysis of translesional pressure-flow velocity relations in patients. J Am Coll Cardiol. 1993; 22: 449-458.

14 Miller DD, Donohue TJ, Younis LT, et al. Correlation of pharmacological 99mTc-sestamibi myocardial perfusion imaging with poststenotic coronary flow reserve in patients with angiographically intermediate coronary artery stenoses. Circulation. 1994; 89: 2150-2160.

15 Joye JD, Schulman DS, Lasorda D, et al. Intracoronary Doppler guide wire versus stress single-photon emission computed tomographic thallium-201 imaging in assessment of intermediate coronary stenoses. J Am Coll Cardiol. 1994; 24: $940-947$

16 Esen AM, Acar G, Esen 0 , et al. The prognostic value of combined fractional flow reserve and TIMI frame count measurements in patients with stable angina pectoris and acute coronary syndrome. J Interv Cardiol. 2010; 23: 421-428.

17 Yew KL. Successful treatment of fractional flow reserve wire induced coronary dissection and other coronary de novo lesion with paclitaxel coated balloon only. Int J Cardiol. 2014; 177: 1127-1128.

18 Davies JE, Sen S, Dehbi HM, et al. Use of the instantaneous wave-free ratio or fractional flow reserve in PCI. N Engl J Med. 2017; 376: 1824-1834.

19 Gotberg M, Christiansen EH, Gudmundsdottir I], et al. Instantaneous wave-free ratio versus fractional flow reserve to guide PCI. N Engl J Med. 2017; 376: 1813-1823.

20 Neumann FJ, Sousa-Uva M, Ahlsson A, et al. 2018 ESC/EACTS Guidelines on myocardial revascularization. Eur Heart J. 2019; 40: 87-165.

21 Pothineni NV, Shah NN, Rochlani Y, et al. U.S. trends in inpatient utilization of fractional flow reserve and percutaneous coronary intervention. J Am Coll Cardiol. 2016; 67: 732-733.

22 De Bruyne B, Pijls NH, Kalesan B, et al. Fractional flow reserve-guided PCI versus medical therapy in stable coronary disease. N Engl J Med. 2012; 367: 991-1001.

23 Westra J, Andersen BK, Campo G, et al. Diagnostic performance of in-procedure angiography-derived quantitative flow reserve compared to 
pressure-derived fractional flow reserve: the FAVOR II Europe-Japan study. J Am Heart Assoc. 2018; 7: e009603.

24 Gotberg M, Cook CM, Sen S, et al. The evolving future of instantaneous wave-free ratio and fractional flow reserve. J Am Coll Cardiol. 2017; 70: 1379-1402.

25 Toth GG, Johnson NP, Jeremias A, et al. Standardization of fractional flow reserve measurements. J Am Coll Cardiol. 2016; 68: 742-753.

26 Kalińczuk $Ł$, Zieliński K, Dębski MA, Skwarek M. Accuracy of the lowest Pd/Pa ratio measurement during induced hyperaemia (correct fractional flow reserve assessment). Kardiol Pol. 2018; 76: 473.

27 Tu S, Westra J, Yang J, et al. Diagnostic accuracy of fast computational approaches to derive fractional flow reserve from diagnostic coronary angiography: the international multicenter FAVOR pilot study. JACC Cardiovasc Interv. 2016; 9: 2024-2035.

28 Westra J, Tu S, Winther S, et al. Evaluation of coronary artery stenosis by quantitative flow ratio during invasive coronary angiography: the WIFI II study (Wire-Free Functional Imaging II). Circ Cardiovasc Imaging. 2018; 11: e007107. 